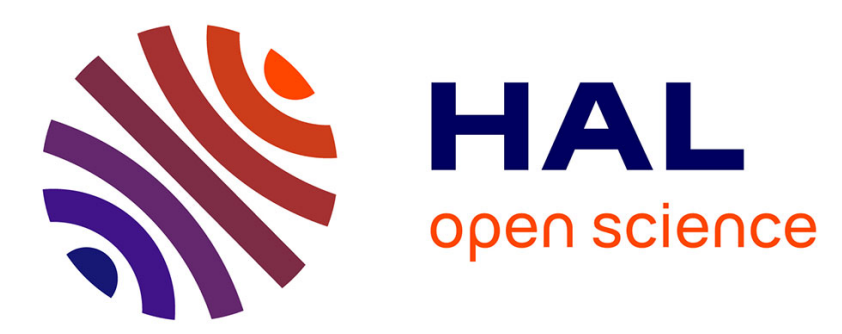

\title{
Codevelopment of conceptual understanding and critical attitude: toward a systemic analysis of the survival blanket
}

Laurence Viennot, Nicolas Décamp

\section{To cite this version:}

Laurence Viennot, Nicolas Décamp. Codevelopment of conceptual understanding and critical attitude: toward a systemic analysis of the survival blanket. European Journal of Physics, 2016, 37 (1), 10.1088/0143-0807/37/1/015702 . hal-01738694

\section{HAL Id: hal-01738694 \\ https://hal.science/hal-01738694}

Submitted on 20 Mar 2018

HAL is a multi-disciplinary open access archive for the deposit and dissemination of scientific research documents, whether they are published or not. The documents may come from teaching and research institutions in France or abroad, or from public or private research centers.
L'archive ouverte pluridisciplinaire HAL, est destinée au dépôt et à la diffusion de documents scientifiques de niveau recherche, publiés ou non, émanant des établissements d'enseignement et de recherche français ou étrangers, des laboratoires publics ou privés. 


\title{
Codevelopment of conceptual understanding and critical attitude: Toward a system analysis of the survival blanket
}

\author{
Laurence Viennot and Nicolas Décamp \\ LDAR Laboratoire de Didactique André Revuz EA 4434
}

\section{Introduction}

One important aspect of physics teaching involves the promotion of conceptual understanding in ways that provide both explanatory depth and coherence in the analysis of physical phenomena. In recent years, however, science teaching objectives have placed stronger emphasis on skills than on a corpus of contents. There are multiple reasons for widespread acceptance of such objectives. In a changing world, it seems impossible to teach directly all the knowledge that may be of use to future scientists; instead, the main goal should be to enable them to exercise responsible citizenship. As recommended by the European Commission, 'science education should focus on competencies' ([1], 20). From this perspective, the development of critical faculties becomes a key objective, and there is a risk that conceptual structuring may be disregarded. The ensuing conceptual reduction observable in the design of learning environments and teaching resources makes it all the more crucial that students and teachers can deliberately adopt a critical attitude. In particular, it is important that students should be able to critically evaluate the extent to which an explanation of the target phenomenon is coherent and complete.

In that context, it must be asked whether it is possible for students to develop a critical stance without a conceptual basis, leading in turn to the issue of possible links between the development of conceptual understanding and of critical attitude. Rather than investigating possible correlations between conceptual understanding and particular skills (see for instance [2] in relation to metacognition), it seemed more instructive to centre on the very process by which conceptual understanding and critical stance interfere during an educational intervention. For that reason, our analysis focused on the possible interplay between the development of conceptual comprehension and critical thinking, including metacognition and affects (metacognitive-critical-affective aspects or MCA) such as the search for intellectual satisfaction, pleasure or frustration in this regard, doubt and self-critique.

In Flavell's words [3], 'Metacognition refers to learners' views and beliefs about learning and to the active regulation of their learning processes'. Concerning the links between critical thinking and metacognition, we note that these are not necessarily acknowledged explicitly. For instance, in a recent review of metacognition [4], expressions such as 'critical thinking', 'critical faculty' or any equivalent are conspicuously absent. In contrast, 'critical thinking' is one of the 'learning activities' explicitly assigned by Vermunt [5] to metacognition. In sharing this view, we see critical stance as a component of metacognition-that is, as an essential condition for active self-regulation of one's own learning processes.

The meaning ascribed here to expressions like 'critical attitude' or 'critical faculty' reflects an epistemological position, in which physics is seen as a science, aiming at a coherent and parsimonious description of the world, with a few laws accounting for a large set of phenomena within a specified range of validity ([6], [7]). In such a framework, 'critical faculty' refers to the capacity to detect self-contradictory statements, statements that contradict basic laws of physics, and very incomplete explanations. Here, we envisage situations in which contestable statements can be identified on the basis of a relatively simple argument, where the adjective 'simple' refers to what may reasonably be expected of the concerned population. 
It seems important to underline that adopting a critical stance to an explanation requires an awareness of one's own state of comprehension (a 'metacognitive' feature) and is also a means of expressing dissatisfaction. In other words, adopting such a stance is also likely to be related to a search for intellectual satisfaction, which has been defined as 'a feeling linked to the impression of having understood a complex topic to a certain extent, one that can be identified quite clearly, this being accomplished with a good quality/cost ratio' [8]. The present inquiry therefore takes account of the extent to which the intellectual path proposed to interviewees fosters their 'intellectual satisfaction'. As these MCA components of students' critical attitude seem a priori difficult to unravel, we examine how these evolve in possible conjunction with conceptual comprehension-in other words, the aim is to characterize students' intellectual dynamics during interaction with an interviewer.

In examining how students' critical stance may change during a discussion intended to gradually nourish their comprehension, the selected topic is how and why a survival blanket can protect against hypothermia. A survival blanket is a very thin sheet of Mylar with a more reflective side ("silver") and a reverse side ("gold") that is less reflective. Most of the reviewed Internet documents relating to this topic were, at best, incomplete, and a preliminary investigation established that the same could be said of advanced students' responses to questions about the topic. This is a relatively complex topic, crucially involving system analysis, which has been found to constitute a significant stumbling block for students in discussing other topics (notably, the greenhouse effect) [9], [10], [11], [12]. The selected topic therefore provides a useful test case for exploring incomplete explanations recurrently formulated by the students, which are also commonly found in popular science explanations.

Following preliminary clarification of the conceptual content and an exploration of anticipated difficulties, in-depth interviews were conducted in line with the "teaching experiments" defined by Komorek and Duit [13]. The participants were seven prospective teachers in their fourth year at university. Analysis of the transcripts focused on their intellectual dynamics - that is, on the interplay between conceptual and MCA factorsincluding the extent to which students activated their critical faculties, with particular attention to their level of agreement and intellectual (dis)satisfaction. In so doing, the study addresses students' conceptual difficulties and potential stumbling blocks in this domain of physics.

The final discussion suggests how these results may inform future research as well as decisions concerning teaching objectives and the design of learning environments.

\section{Common difficulties in understanding thermal transfer}

\section{Students' ideas concerning thermal transfer (excluding work or change of phase)}

The theme of energy transfer has connections with the whole of thermodynamics; here, we consider only transfers of energy without work, so narrowing the range of common misunderstandings. The label "thermal transfer" is used to designate processes that involve convection, conduction or radiation (although, in this last case, it may be preferable to speak of "radiant transfer of energy" without reference to "thermal"). Processes involving work or change of phase are not considered here-in other words, only the "restricted category" of phenomena defined in [14] are dealt with, where only the mean particulate kinetic energy changes in each system.

Even within this limited frame, many investigations since the 1980s have shown that young students' ideas differ widely from accepted physics. For most of these pupils, heat seems to be simply understood as something hot that heats other things. As reported by Erickson [15], this "something" is equated either with a hot body or with a kind of substance 
emitted by a heat source. According to this author, "up to the age of 12-13 pupils are familiar with the term temperature and are able to use a thermometer to assess the temperature of objects, but they actually have a fairly limited concept of the term and rarely use it spontaneously to describe the condition of an object". And when children were asked directly about the difference between heat and temperature, "the most common type of response (accounting for more than $25 \%$ at all age levels) was that there is no difference between them" [15].

Researchers have also reported some responses that seem to deny the possibility of a thermodynamic equilibrium between objects in prolonged contact. For instance, when asked if two plates situated in the same room, one metal and one plastic, are at the same temperature, most pupils believe, even after teaching, that this is not the case [16]. And Tiberghien [17] reports that "different materials (flour, nails, water) placed for several hours in an oven at 60 ${ }^{\circ} \mathrm{C}$ are at different temperature for the majority of pupils ."

Within this "restricted" category research (i.e. only thermal transfer occurring and only kinetic energy varying), questions have also been asked about which materials are useful for the thermal insulation of various objects. To answer correctly, one needs to consider the thermal conductivity of each material, focusing on the idea of transfer between two other systems. This idea of transfer also arises in relation to the difficult question of tactile sensations produced by various materials at the same temperature. Most pupils' explanations seem to take account of the material under consideration along with only one of the other involved systems: either the body to be insulated or ambient air, with or without the mediation of "heat". Tiberghien quotes some examples of such explanations:

The aluminum keeps cold better. (11 year-old)

Metal cools things, metal is cool. (12 year-old)

These explanations predominate before teaching and can be gradually replaced through teaching by others that suggest no asymmetry with respect to "hot" and "cold" [17]. However, it is striking to note that even in middle school students [18], upper secondary school or even more advanced students [19], similar lines of reasoning were still very commonly observed, in particular concerning the supposedly cooling role of aluminum.

\section{Linear common reasoning}

We suggest that taking account of both interacting systems (here, "hot" and "cold" sources) is one of the most critical issues in this domain and also deserves particular attention when analysing advanced students' comments. One very salient obstacle in such situations is the common tendency to explain phenomena on the basis of linear common reasoning [9] [20], [21], [22] — that is, with a story-like explanation that causally connects a series of simple events, with no retroaction. In cases of transfer such as electric circuits or thermal transfer, the spatial structure of the device provides a support for the spatiotemporal structure of the explanation; something starts from (..), and then (..), and then (...). When investigated in relation to issues such as the greenhouse effect, these patterns reveal strong and prevalent common ideas [9], [10], [11], [12]. The transient situation is not clearly differentiated from the steady state and is commonly (though implicitly) invoked to explain the difference in temperature inside and outside a greenhouse. For instance, it is commonly argued that solar radiation is trapped in the greenhouse, or thermal radiation emitted by the ground is seen as a continuation of the story of incoming solar radiation. This "continuation" raises a serious difficulty [10], as it involves an energy flux greater than the solar radiation.

\section{The case of the survival blanket}

Turning to consider the survival blanket, the above line of reasoning entails a strong focus on the "heat" emitted by the body that is to be protected against hypothermia. The main 
question then becomes how to trap this "heat" inside the blanket, with no particular concern about what happens subsequently "downstream". In a preliminary questionnaire, $20 \mathrm{PhD}$ students were asked to say how they would use a survival blanket to protect against cold, and to justify their response. All but one responded that they would place the most reflective side (silver) toward themselves; justifications included the following:

- So that heat would be reflected back to me;

- Infra red radiation will be reflected toward me;

- Heat comes from inside;

- So as to send back to me the radiation that I emit;

- Shiny side outside, it would not be of any use as energy is coming from inside.

Although such comments are not wholly irrelevant, they neglect important issues and fail as a guide to efficient decision-making in an emergency situation (as the content analysis in the next section demonstrates). It is noteworthy that no complete explanation or appropriate instructions for use of such blankets could be found online. Twenty-five product descriptions for survival blankets were consulted, including those bearing the Red Cross label. Like our students, all noted the importance of the reflective power of the silver side in reflecting the "heat" from the body at risk of hypothermia (i.e. silver side "in") or in reflecting external radiation from a hot source (silver side "out"). Product descriptions included the following points:

-The Mylar Emergency blankets are designed to reflect heat back to body, or deflect heat when used as a shelter from the sun. PrimaCare Medical

-The theory behind thermal blankets is that heat is redirected back toward the object emitting the heat. http://www.ehow.com/info 8574832 thermal-blanket.h (via Wikipedia in English)

-People lose heat through thermal radiation. All objects radiate infrared energy. The warmer the object, the more energy is radiated, cooling the object. A thermal blanket is more than 80 percent reflective. That means that more than 80 percent of the thermal energy that reaches it is deflected back towards its source. When someone is wrapped in a thermal blanket, his own reflected infrared heat is reflected back towards him, warming him up more quickly. Read more: http://www.ehow.com/how-does 5145153 thermal-blanket-work.html

-Provides compact emergency protection in all weather conditions by reflecting back and retaining 90-Percent of a survival victim's body heat. ER Emergency Ready

-This compact blanket provides warmth (retains and reflects up to 90 of body heat) ( IS E-Store)

The following instructions for use are commonly given, as for instance by "Les produits Croix-Rouge":

- Silver surface outside isolates from heat;

- Silver surface inside isolates from humidity, cold and rain.

Wikipedia, in its French version, gives the same instructions for use:

- Due to its temperature, a human body emits thermal radiation in the infrared domain (near $10 \mu)$. To protect against hypothermia, the gold surface has to be outside. Thus, infrared radiation is kept inside, and a part only of what comes from the external environment is absorbed and complements the calorific supply. To prevent sunburns, it is advised to place the silver surface outside, as it reflects $90 \%$ of the infrared radiation. http://fr.wikipedia.org/wiki/Couverture_de_survie

In fact, the relevant phenomena are complex, and a more complete content analysis is needed to ensure appropriate instructions for use. The following section shows that the instructions for use just cited would entail a significant risk that the blanket would not be used in an optimal way. In the frame of our research question, it provides a reference to appreciate the lines of reasoning of our interviewees.

\section{Content analysis}

The following is an elementary model of the situation as described, with a minimal, coherent account of its main characteristics and in particular of the need for system analysis [23]. Box 1 provides a reminder of the main constituent concepts in this problem, and Box 2 
provides a simple means of comparing the emissivity of each side (silver or gold) of a survival blanket. For present purposes, the essential fact to keep in mind is that here (concerning an opaque material), for the same wavelength, low emissivity means high reflectivity.

Box 1: Absorptivity, emissivity and Stefan's law (see Besson [24])

For an incoming radiation $R$, having a frequency spectrum $\phi_{i}(v)$ and irradiance $\Phi_{i}=\int_{0}^{\infty} \phi_{i}(v) \mathrm{d} v$, the energy absorbed per area and time unit by a body surface will be

$$
\int_{0}^{\infty} a(v) \phi_{i}(v) \mathrm{d} v=a_{r} \phi_{i},
$$

where $a_{r}$ represents global absorptivity for the entire considered radiation $R$ and is equal to the mean value, weighted with $\phi_{i}(v)$, of the absorptivities $a(v)$ relative to all frequencies.

The total energy emitted per area and time unit is

$$
\Phi_{e}=\int_{0}^{\infty} e(v) B(T, v) \mathrm{d} v=e_{t} \sigma T^{4},
$$

where $e_{t}$ is the mean value, weighted with the Planck function $B(v, T)$, of the surface emissivity $e(v) ; T$ is the absolute temperature and $\sigma$ the Stefan constant.

$a(v)=e(v)$ for every $v$; these coefficients can strongly vary with frequency.

Black body: $a(v)=e(v)=1$ for every $v$ and $\Phi_{e}=\sigma T^{4}$.

Box 2. The importance of surface state in emissivity of a body: a boiler filled with water, with various materials stuck on the external surface for use with an infrared "thermometer".
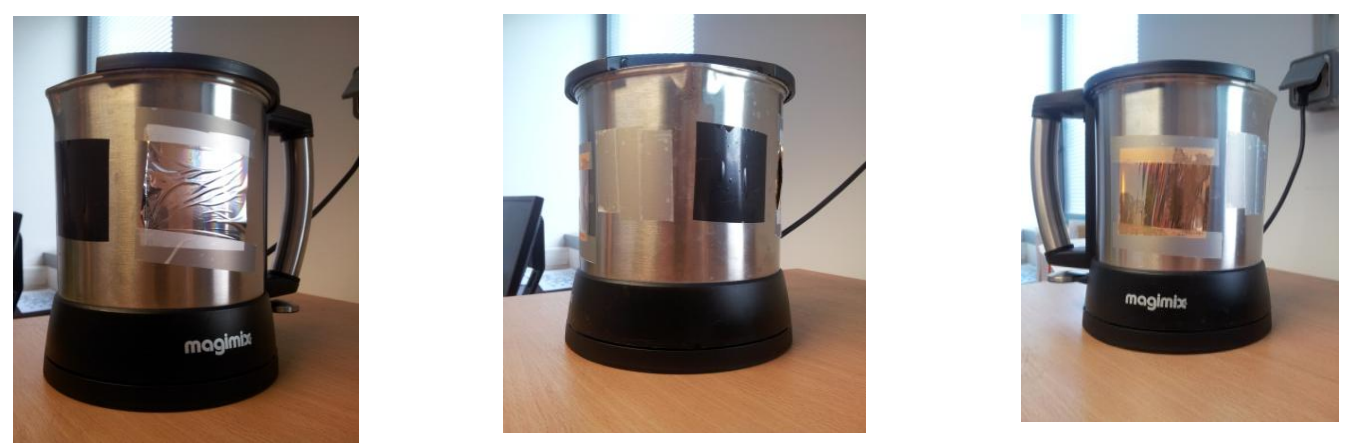

Measures of the respective emitted powers, indicated with equivalent temperature (IR "thermometer"/radiometer) when the water is boiling

\begin{tabular}{lccccc}
\hline $\begin{array}{l}\text { Number displayed by the } \\
\text { "thermometer" }\end{array}$ & $\begin{array}{c}\text { Bare } \\
\text { metal }\end{array}$ & $\begin{array}{c}\text { Transparent } \\
\text { tape }\end{array}$ & $\begin{array}{c}\text { Black } \\
\text { electric } \\
\text { tape }\end{array}$ & $\begin{array}{c}\text { Emergency } \\
\text { blanket- } \\
\text { "Silver" } \\
\text { outside }\end{array}$ & $\begin{array}{c}\text { Emergency } \\
\text { blanket- } \\
\text { "Gold" } \\
\text { outside }\end{array}$ \\
\hline $\begin{array}{l}\text { Situation: } \\
\text { Boiling water in a boiler }\end{array}$ & $38^{\circ} \mathrm{C}$ & $95^{\circ} \mathrm{C}$ & $96{ }^{\circ} \mathrm{C}$ & $27^{\circ} \mathrm{C}$ & $38^{\circ} \mathrm{C}$ \\
\hline
\end{tabular}


In our simplified structural model, three subsystems are considered, each isothermal at different temperatures: the body (To), the blanket (Tb) and the external air (Te). Two successive subsystems exchange energy with net fluxes orientated from body to external air. It might first be remarked that impeding radiant transfer between blanket and external air by placing silver (low emissivity) outside would serve to maintain a higher temperature difference between these two subsystems. Impeding radiant transfer between body and blanket by placing silver (high reflexive power) inside would also serve to maintain a higher temperature difference between this second pair of subsystems. This seems to lead to a dilemma, as we cannot place the silver side both inside and outside.

In more detail, two successive subsystems exchange energy by two processes that intervene in parallel in each transfer zone: radiant transfer and conductive-convective (C) transfer. In each case, net fluxes flow from the body to the external air (Figure 1). Each of these (four) fluxes are increasing functions of difference in temperature, with a coefficient of either conduction-convection (C)-linked to clothes, shape factor and meteorological conditions (unaffected by the orientation of the blanket) —or radiant, linked to the emissivity of the side turned towards the transfer zone and to shape factor. For a given total flux $\Phi_{T}$ at steady state, a lower radiant flux means a larger $\mathrm{C}$ flux in each zone of transfer, which in turn means a larger difference in temperature between the interacting subsystems. Turning the low emissivity side (silver) towards a transfer zone entails a larger difference in temperature (at given total flux) between the interacting subsystems. That said, to protect against cold, what should be maximized in steady state is the difference in temperature between body and external air. But because the blanket has only one side that is minimally emissive and highly reflective (silver), it is not obvious in which of the two transfer zones the difference in temperature between the exchanging subsystems should be maximized. This gives rise to the dilemma above, as it is not obvious how to place the survival blanket to protect against cold. Formulated in this way, the problem structure is a search for the best compromise; the aim of the first part of the interview is that interviewees become aware of this point.
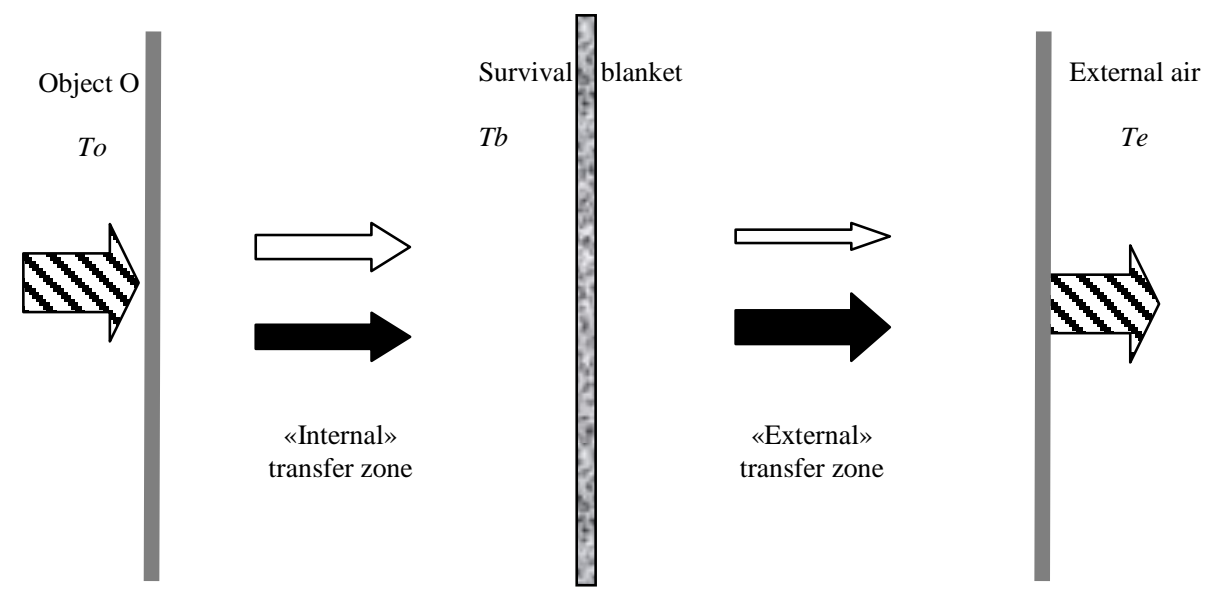

Figure 1. A structural model of energy transfer for the survival blanket. A constant power is emitted by the body; how can $T o-T e$ be maximized in steady state? Only net fluxes are represented, as follows: white arrow $=$ net radiant flux $\left(\Phi_{\mathrm{rad}}\right)$; black arrow $=$ net conductiveconvective flux $\left(\Phi_{C}\right.$ ); the relative values of represented fluxes are arbitrary, and shape factors are not taken into account here. 
Drawing on Vollmer [25], and taking into account the weak relative value of temperature differences considered here, a linear mathematical model (Appendix 1) was used (despite the non-linear form of Stefan's law) (Box 1). Formally, this model is equivalent to that of two conductive dipoles in series (Figure 2) - one between body and blanket, and another between blanket and external air. Each of these dipoles is a set of two conductive dipoles in parallel (two modes of transfer).

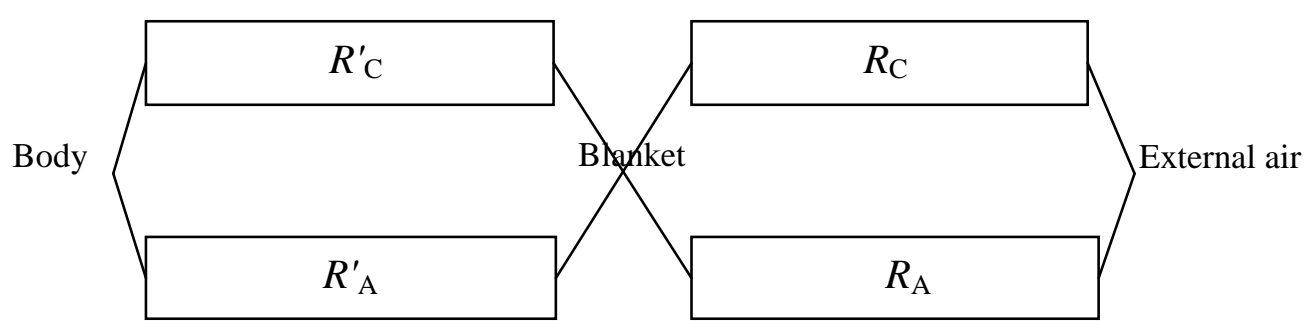

Figure 2. Representation of the system between body and external air: $R^{\prime}{ }_{C}$ and $R_{C}$ represent resistances to energy transfer by conduction/convection; $\mathrm{R}_{\mathrm{A}}$ and $\mathrm{R}_{\mathrm{A}}$ represent resistances to radiant energy transfer. These resistances are the inverses of the coefficients in use.

This model invites the conclusion that the low emissivity (silver) side should face towards the transfer zone having the lowest $\mathrm{C}$ coefficient of transfer. In case of dry weather (low $\mathrm{C}$ coefficient), the silver side (low emissivity) should face outward; for windy and wet conditions, silver should face inward. An easy way to remember this conclusion is that placing the smallest radiant resistance in parallel with the greatest conductive resistance would short-circuit both of the greatest resistances, so lowering the total resistance. We have found no complete explanation of this process anywhere. Instead, online sources or instructions for use (as shown above) currently suggest that where there is a risk of hypothermia, silver should face inward, but no mention is made of the crucial role of meteorological conditions.

\section{Method}

To investigate what is a detailed and entangled process, fine grained analysis was conducted of students' comments $(\mathrm{N}=7)$ during a long $\left(\cong 75^{\prime}\right)$ interaction with an interviewer. The discussion was oriented towards conceptual acquisition, that is strongly structured and guided and allowed interviewees to express both their initial thoughts and their responses to a range of questions and requests. The specific format involved a concept-driven interactive pathway [26] - that is, a concept-oriented interaction with the interviewer-to conduct the student through a series of determinate conceptual steps and to provide students with opportunities to criticize. The approaches used included qualitative, mathematical modelling, analogical and experimental methods. More detail can be found in [23].

\section{Interviews}

A scenario for the interviews was constructed on the basis of our content analysis and existing knowledge of frequently observed lines of reasoning about this and related topics. The target 
for the first phase (between 30' and 40') was to reach a point where the solution to the problem ceases to be obvious and can be expressed as a search for the best compromise. This objective was aligned with our rationale in combining conceptual and MCA aspects. This first phase comprised a number of steps. Following a question about how to place the blanket to protect against cold, with an experimental illustration of the relative emissivity of silver and gold sides of the blanket (Box 2), the structural model (Fig. 1) was introduced. An option to envisage the system's final steady state with given total energy flux was followed by a dialogue about the various arguments detailed above to induce the idea that local analyses are insufficient to solve the problem. These arguments were successively introduced by the interviewer for discussion with the student. The steps of this first phase are summarised in Table 1.

Table 1. First phase of the interview protocol

\begin{tabular}{|c|c|}
\hline Step & on between interviewer and student \\
\hline 1 & $\begin{array}{l}\text { A prediction is sought concerning which placement of the survival blanket will protect against } \\
\text { hypothermia, informed by an experiment about the relative emissivity of silver and gold sides. }\end{array}$ \\
\hline 2 & $\begin{array}{l}\text { The possibility is introduced of a divergence of temperature where "heat" is reflected from blanket to } \\
\text { body in the absence of other processes of transfer. Conduction and convection (C) are introduced and } \\
\text { treated jointly. }\end{array}$ \\
\hline 3 & $\begin{array}{l}\text { A structural model is introduced, involving body, blanket and external air, separated by two transfer } \\
\text { zones ("int" and "ext"), in each of which two processes of transfer (radiant and C) occur in parallel. }\end{array}$ \\
\hline 4 & $\begin{array}{l}\text { Net fluxes are represented as arrows from body to external air. The interviewer suggests analysis of a } \\
\text { steady state at a given value of total flux } \Phi_{\mathrm{T}} \text {, framing the problem as a search to maximize the } \\
\text { difference in temperature between body and external air. }\end{array}$ \\
\hline 5 & $\begin{array}{l}\text { ux emerging from the system will be the same, regardless of } \\
\text { d. }\end{array}$ \\
\hline 6 & $\begin{array}{l}\text { C transfer in the external zone of transfer, the net } \mathrm{C} \text { flux from } \\
y \text { on the temperature of the blanket. }\end{array}$ \\
\hline 7 & $T_{e}$, the net $r a$ \\
\hline 8 & $\begin{array}{l}\text { Discussed: Given } \Phi_{T,} T_{e} \text { and the coefficient of C transfer in the external zone of transfer, turning silver } \\
\text { outward will result in a larger ratio } \Phi_{e x t} / \Phi_{e x t} \text { rad. }\end{array}$ \\
\hline 9 & $\begin{array}{l}\text { ansfer, turning silver outward will result in a larger } \\
\text { d external air (as compared to gold outside). }\end{array}$ \\
\hline 10 & d: Statement 9 does not depend on what is inside the blanket. \\
\hline 11 & $\begin{array}{l}\text { Discussed: Considering now the "inside" compartment, at given } \Phi_{T} \text {, turning the silver side towards the } \\
\text { body results in a larger difference in temperature } \Delta T_{\text {int }} \text { between body and blanket (less radiant and more } \\
\mathrm{C} \text { transfer in the internal zone of transfer) as compared to turning the gold side inward. }\end{array}$ \\
\hline 12 & $\begin{array}{l}\text { Discussed: a) The limits of discussing each zone of transfer (internal and external) separately; b) the } \\
\text { need to search for the best compromise. }\end{array}$ \\
\hline
\end{tabular}

The second phase of the interview was rather directive, with many inputs on behalf of the interviewer. He continuously asked about the student's agreement or disapproval concerning the explanations they were given. The students were presented with a linear mathematical model and its electrical analogue (see Figure 2 and Appendix 1). In this model, two ways of addressing the problem appear to be clearly equivalent: looking for the maximum difference in temperature between body and blanket at given total flux at steady state and looking for the minimum total flux for a given difference in temperature in a quasi-stationary regime. This step is followed by an illustrative experiment with electric circuits. Indeed, for an expert in physics, the structure of the linear model as described strongly suggests an electrical analogy involving constant resistances, in which the difference in temperature, the flux of energy, the various coefficients of transfer and their inverses respectively correspond to a potential 
difference, a flux of charge (intensity), inverses of resistance ("conductances" in French) and resistances. The interviewer then seeks to establish the extent to which students can themselves arrive at this analogy while leading them towards its. An experiment is conducted with a charged capacitor $(\mathrm{C}=10 \mathrm{~F})$ in series with a compound resistor built with four resistors, two with the same low resistance $(\mathrm{R} 1=\mathrm{R} 2=1 \Omega)$ and two with the same greater resistance $(\mathrm{R} 3=\mathrm{R} 4=100 \Omega)$. A low $(\mathrm{R} 1)$ and a greater $(\mathrm{R} 3)$ resistance are in series and cannot be changed (the equivalent of structural and meteorological conditions); the others should be put in parallel with R1 or R3 (i.e. choosing which side of the blanket turns in or out). When asked how to minimize the flux of charge (i.e. the intensity), students can immediately check the value of their prediction by observing the time rate of the discharge. The conclusion drawn from the mathematical model now takes a simple form: it is better to put low resistances in parallel, and the same applies to the greatest resistances. A good way to memorize this rule is to think of a short circuit: putting low resistances in parallel with greater resistances will short-circuit both greater resistances, thereby lowering the total resistance. If small resistances are in parallel, they constitute a dipole of small resistance, but the resistance of the other dipole in series (made of the two greatest resistances in parallel) will be of same order of magnitude (half, in this example) as the smallest of these resistances.

Students were also presented with a report on some home experiments (Appendix 2) on the cooling of objects wrapped in survival blankets in a freezer. During the third phase, the students were invited to express their intellectual (dis)satisfaction with the interview and the value of its general organization (with a long qualitative dialogue before the mathematical treatment), and to criticize some of the product descriptions or instructions for use found online.

\section{Processing the interviews}

The interview transcripts were submitted to thematic content analysis and coded. Each exchange turn was numbered, and the corresponding time elapsed since the beginning of the interview was registered. In the interests of brevity, this paper is focused on the first phase of the interview, which is particularly informative with regard to MCA aspects of students' responses and how interviewees became aware that the problem addressed is systemic. The results concerning the second and third phases will be reported in less detail.

After a first fine-grained analysis, five recurrent lines of reasoning (LRs) were identified; the term "recurrent" indicates that each was observed in more than one student and, in most cases, was reiterated several times by a given student, with a significant delay in between (at least fifteen exchange turns). These five LRs were highlighted because they turned out to play a decisive role in students' argumentation. Some of these patterns were expected by virtue of our a priori analysis, and others emerged from the data [27]. The five LRs are illustrated below in the results section, revealing their recurrent character.

Codes were also assigned to the MCA components of the interaction between interviewer and student, including expressions of criticism. Concerning student acceptance of statements from the interviewer, (a) means "simple acceptance" (a brief approval with an onomatopoeia or not more than three words), whereas (a) indicates "frank acceptance" (an explicit statement of more than three words and/or a particular tone). Various indicators of dissatisfaction or perplexity on behalf of the students were also defined, such as a silence longer than five seconds ("sil"), a direct request for the solution ("q": e.g: "I want to know how it works"..."), a criticism of one's own previous answer ("selfc": e.g. "I was wrong") or an explicit doubt ("d": e.g.: "I cannot justify my answer ..."). These categories are not exclusive for a given comment. Coding was negotiated between the two authors and is illustrated by numerous excerpts below. 
On the basis of this preliminary identification of recurrent LRs and the coding procedure, we constructed a tentative mapping of student's intellectual dynamics in the first phase of the interview.

\section{Main results: summary and analysis}

\section{Some recurrent lines of reasoning}

Table 2 sets out the five recurrent LRs that were found to play an important role in the observed discussions. The next section specifies their meaning and provides examples of their occurrence.

* LR1: "The heat" should be kept/reflected back towards the body.

This is the LR identified in many online documents and in our preliminary investigation involving $\mathrm{PhD}$ students. It frames energy transfer as a story of a given amount of "heat" leaving the body and keeping it near that body, giving rise to the view that the side of the blanket with greatest reflective power (silver) should be turned towards the body.

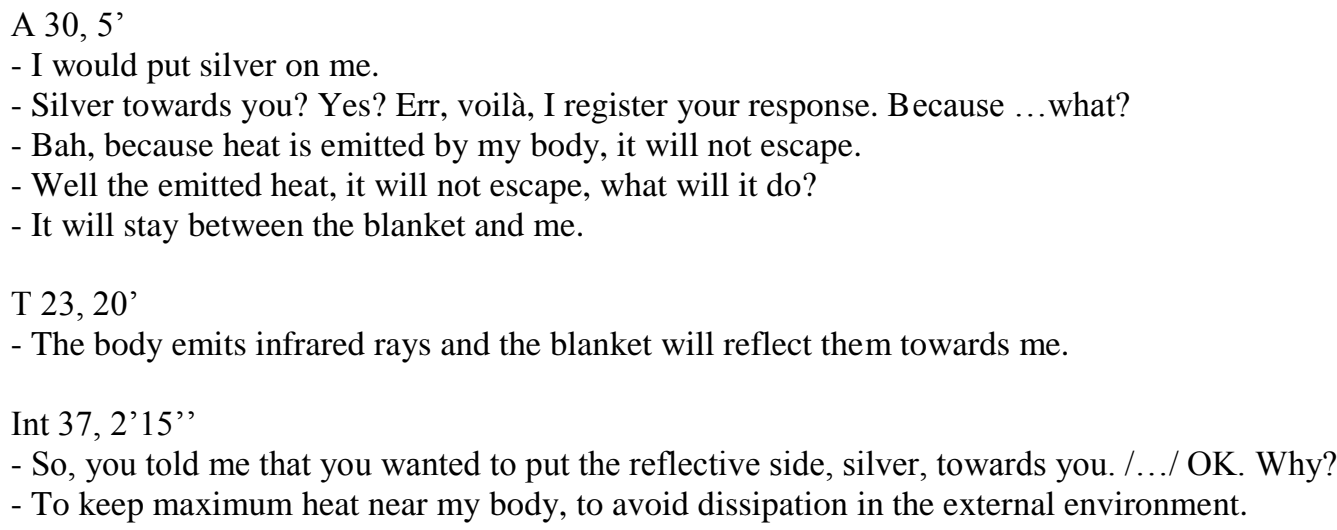

As already mentioned, this type of comment does not acknowledge the external part of the system between the blanket and the external air, and in this sense, it is not systemic, following only the first steps of a flow. All of the students chose this orientation for the blanket. Only one $(\mathrm{H})$ was less clear about her reasons, which at first she attributed only to her intuition. However, during the discussion which followed, she repeatedly used the current argument (LR1):

H 41, 3'10', - .There is one (side) that will necessarily better retain heat than the other.

Int 141,12 '10' - Silver reflects much and emits little.

$\mathrm{H}$ - Bah it reflects much, it is one more reason to keep it near us given that it will reflect the energy that it will receive from us.

Note that this choice of putting silver inside might be relevant in certain circumstances (wet and windy weather), but this can be shown only on the basis of a system analysis, far more complete than this purely sequential analysis. 
* LR2: $\Phi_{C}$ is unaffected by the emissivity of the side of the blanket in play (as if it were independent of the parallel transfer by radiation, $\Phi_{\text {rad }}$, in steady state).

C 186, 21'09"

- Yes, if we have the yellow side outside, we will have a much larger radiant flux than if the side/

- Yes, and for convective (flux), it follows that/

- Convective, it does not change much.

* LR3: To protect against cold, we should reduce the transfers by convection $\Phi_{C}$, (as if $\Phi_{C}$ were independent of the parallel transfer by radiation, $\Phi_{r}$, in steady state at given $\Phi_{T}$.)

Int 325, 35,

- It bothers you to lose much flux via black flux $(C)$, it bothers you to lose that one.

- Err, yes, for me, black flux (conductive-convective).does matter more than white flux (radiant).

- Since the beginning, you told me, we agreed on, that when black flux was big, the temperature

difference was big.

- Yeees.

- That's advantageous.

- Why would it be advantageous to lose much flux?

C 230, 26’20

- We want to minimize convection here, between object and blanket.

In fact, for a given total flux and conduction/convection coefficient, the blocking role of weaker emissivity (silver side outward instead of gold) results both in a larger $\mathrm{C}$ transfer and a larger temperature difference between the subsystems in interaction. Instead, lines of reasoning LR2 and LR3 ignore the interplay between radiation and conduction-convection.

* LR4: Seeing the body and the blanket as a single isothermal subsystem

T 62, 8'my

- The only thing I consider is the compartment consisting of the blanket around my body, and the exterior.

Int $89,10{ }^{\prime} 42$

- The blanket and your body, it's a single block for you?

- Err, yes.

- So it was not necessary to bother about the exchanges inside the block, then?

- Yes it was.

Interestingly, this line of reasoning does not exclude consideration of energy transfers inside this "block", as is also shown by T's firm attachment to LR1.

* LR5: Steady state is seen as compatible with the idea that total flux is not the same through each subsystem at a given time.

In this case, the very notion of steady state at given total flux reveals a stumbling block.

S 216, 24'30"

- Actually, I don't see why the outward flux would be constant between the different materials.

- Ah, finally, it's the very existence of the steady state that you challenge.

- No no, because the steady state is not necessarily the same when you change materials. We can have a steady state A with silver and a steady state B with gold.

- Of course, but with the same flux.

- With the same incoming flux but not with the same outing flux, it's what's interesting. 
Table 2. Five recurrent LRs observed in the first part of the interview

\begin{tabular}{|ll|}
\hline LR1 & $\begin{array}{l}\text { The "heat" should be kept/reflected back toward the body; silver side inside } \\
\text { (implicitly: in any circumstance) }\end{array}$ \\
\hline LR2 & $\begin{array}{l}\Phi_{C} \text { unaffected by emissivity of the side of the blanket in play (as if it were } \\
\text { independent of the parallel transfer by radiation, } \Phi_{\text {rad }} \text {, at given } \Phi_{T} \text { in steady } \\
\text { state). }\end{array}$ \\
\hline LR3 & $\begin{array}{l}\text { To protect against cold, we should reduce transfers by convection } \Phi_{C} \text { (as if } \Phi_{C} \\
\text { were independent of the parallel transfer by radiation, } \Phi_{\mathrm{r}} \text {, in steady state at given } \\
\\
\Phi_{T} \text {, whereas at constant total flux and given } C \text { coefficients, there is a need to } \\
\text { increase } C \text { transfer via temperature difference, by reducing radiant transfer). }\end{array}$ \\
\hline LR4 & $\begin{array}{l}\text { Seeing the body and the blanket as a single isothermal sub-system } \\
\text { (observed as being compatible with LR1) }\end{array}$ \\
\hline LR5 & $\begin{array}{l}\text { Steady state seen as compatible with the idea that the total flux is not the same } \\
\text { through each sub-system (e.g. " } \Phi_{T} \text { may change downstream"). }\end{array}$ \\
\hline
\end{tabular}

\section{Complementary observations}

This list of recurrent LRs does not exhaust the information that can usefully be drawn from the first phase of these interviews with regard to conceptualization. We observed in particular that 6 of the 7 students declared a preference to envisage a system with constant $\Phi_{T}$ and then sought to ensure a maximum temperature difference between body and external air at steady state rather than seeking to minimize the cooling rate of a body at given temperature, with no energy supply inside the body. This preference was echoed in the design of the interview (Table 2), even if, as $\mathrm{C}$ remarked:

C $150,15 ’ 30$

- Err, I've got the impression that the question is put differently but actually it comes down to the same.

It was also observed that consideration of net fluxes created a difficulty for only one interviewee (A). In terms of difficulties, some students (2/7: R and C) suggested that, where a supply of energy was continuously reflected toward the body, the problem of a possible divergence in temperature would be solved if only part of the incident energy was retained in the zone in question. For brevity, no further comment will be made on these matters, as none proved to be a lasting obstacle for participants.

A tentative mapping of student intellectual dynamics in the first phase of the interview 
Once the five recurrent LRs in Table 2 had been identified and described, their occurrence in students' responses was recorded, along with the various MCA aspects defined above. Table 3 maps the entangled conceptual and MCA evolution of participants' responses during the first phase of the interview.

Table 3. Mapping of the interviewees' intellectual dynamics in the first part of the interviews

\begin{tabular}{|c|c|c|c|c|c|c|c|c|c|c|c|c|c|}
\hline $\begin{array}{l}\text { Step } \\
\text { Stud. }\end{array}$ & 1 & 2 & 3 & 4 & 5 & 6 & 7 & 8 & 9 & 10 & 11 & $12 \mathrm{a}$ & $12 b$ \\
\hline A & LR1 & $\mathbf{a}$ & $\mathrm{a}$ & & $\mathrm{a}$ & $\mathrm{a}$ & $\mathrm{a}$ & $\mathrm{a}$ & $\begin{array}{c}\mathrm{a} \\
\text { selfc }\end{array}$ & d & $\mathrm{a}$ & & $\begin{array}{l}\text { sil } \\
\text { d }\end{array}$ \\
\hline $\mathrm{M}$ & LR1 & $\mathbf{a}$ & & & $\mathbf{a}$ & $\mathbf{a}$ & $\mathbf{a}$ & $\mathbf{a}$ & $\begin{array}{c}\text { a } \\
\text { selfc } \\
\text { d }\end{array}$ & d & & $\begin{array}{l}\mathrm{a} \\
\mathbf{q}\end{array}$ & $\mathbf{a}$ \\
\hline $\mathrm{T}$ & LR1 & $\mathbf{a}$ & $\begin{array}{c}\text { LR4 } \\
\mathrm{a}\end{array}$ & $\mathbf{a}$ & $\mathbf{a}$ & $\mathbf{a}$ & $\mathbf{a}$ & $\mathbf{a}$ & $\begin{array}{c}\text { LR5 } \\
\text { a }\end{array}$ & $\begin{array}{l}\text { LR4 } \\
\text { selfc }\end{array}$ & & $\mathrm{a}$ & $\begin{array}{c}\text { LR1 } \\
\text { d-selfc }\end{array}$ \\
\hline $\mathrm{R}$ & LR1 & $\mathbf{a}$ & $\mathrm{a}$ & $\mathrm{a}$ & $\mathbf{a}$ & $\mathrm{a}$ & & $\mathbf{a}$ & $\begin{array}{c}\text { sil } \\
\mathbf{a}\end{array}$ & & $\begin{array}{l}\text { sil } \\
\text { d-selfc }\end{array}$ & & $\mathbf{a}$ \\
\hline$S$ & LR1 & $\mathbf{a}$ & $\mathrm{a}$ & $\mathrm{a}$ & $\begin{array}{c}\text { LR5 } \\
\text { a }\end{array}$ & $\mathbf{a}$ & $\mathbf{a}$ & $\begin{array}{c}\mathbf{L R 2} \\
\mathrm{a}\end{array}$ & $\mathbf{a}$ & & $\mathrm{a}$ & $\begin{array}{c}\text { d } \\
\text { LR5 } \\
\text { LR3 } \\
\text { a }\end{array}$ & $\begin{array}{l}\text { LR1 } \\
\text { LR1 } \\
\text { LR2 } \\
\text { LR3 } \\
\text { LR4 } \\
\text { selfc }\end{array}$ \\
\hline $\mathrm{C}$ & LR1 & $\mathbf{a}$ & $\mathrm{a}$ & $\mathbf{a}$ & $\mathbf{a}$ & $\mathbf{a}$ & $\mathbf{a}$ & LR2 & $\mathbf{a}$ & & $\mathbf{a}$ & $\begin{array}{c}\text { LR3 } \\
\text { LR3 } \\
\text { a }\end{array}$ & $\mathbf{q}$ \\
\hline $\mathrm{H}$ & $\begin{array}{c}\text { LR1 } \\
\text { LR1 d } \\
\text { LR1 } \\
\text { d-selfc }\end{array}$ & $\mathbf{a}$ & $\mathrm{a}$ & $\mathrm{a}$ & $\mathbf{a}$ & $\mathbf{a}$ & $\mathbf{a}$ & $\mathbf{a}$ & $\mathbf{a}$ & d-selfc & $\mathrm{a}$ & $\mathbf{a}$ & \\
\hline
\end{tabular}

Key. Step: see Table 1; LR: see Table 2; a, a: respectively simple or strong agreement , d: doubt, selfc: self criticism, sil: silence longer than $5 \mathrm{~s}$, q: direct request for the solution of the problem. First line: see in Table 1 the statements correspondingly discussed. LRs are mentioned several times only when more than 15 exchange turns occurred in between. In grey, boxes with: d, selfc or $\mathbf{q}$.

A first observation to emerge from Table 3 concerns the recurrent character of the pinpointed LRs. In particular, the first student response (LR1: unanimous) was subsequently revisited by several students. This followed consideration of some counter-arguments in between:

Int 337, 40'

-Because if I win on one side, I lose on the other one; but if I win on the other side, I lose on the first side. Hence I was going to ask you if you agree on this: putting silver outside increases 
temperature difference between external air and blanket, putting it inside increases temperature difference between blanket and object.

- Yes, err, I've got the impression already to know.

- Tell me.

- Me, I have to put the reflective side inside. Because for me, the main defect inside will be radiation.

Int 303, 32'30"

- What do I do?

- Err that's it, silver inside, gold outside.

S 320, 34'41

- At the same time, I am convinced that it's, that silver, it's upstream.

S 346, 37'30"

- Err for me, the line of reasoning, that's it.

- It's OK?

- Yes

- It's done? That is, you've got an answer to this question of best compromise?

- Err no.

- You were inclined to thinks it's (silver) upstream.

- I think it's upstream but with/

- You were inclined to thinks it's upstream.

- Yes.

Similarly, H manifested a strong attachment to LR1, although she soon felt that some arguments were problematic:

H 118, 10'30"

- Well I'll sum up, if our body is like the boiler, that's it a priori, we would like something that would not emit much infrared in order to avoid that everything would escape, we are going to choose the material so that everything wouldn't escape in the environment.

- Yes yes.

- And so, this one has to/ I don't remember the results well. We've said that/ which one?

- The less emissive one, it's silver.

- So I would chose silver on me.

- OK

(5 exchange turns)

Int 129

- So the silver side, you put it?

- Err on the side, err, towards us, how to say this?

- It's this less emissive side that you put towards you?

- Mm, there is a problem.

- Personally I don't mind, but/ a few minutes ago it's what you said. Now we've just seen that the emissivity of this object is lower than the emissivity of this surface, there, golden.

- Yes.

- So make up your mind, you tell me, you've told me, we should lose as little as possible.

- Yes, for sure.

- So?

- I think I still keep to silver turned toward us.

Table 3 shows other cases of students reusing lines of reasoning that seemed to have been renounced following a discussion with the interviewer. In a variant of this trend towards maintaining an initial view, C made use of LR2 during the first part and used LR3 at the end of this phase. As previously remarked, these two lines of reasoning are similar in that they ignore the interplay between radiation and conduction-convection. 
With regard to MCA aspects, Table 3 shows that students became progressively aware that their first response had limited explanatory power. The grey boxes in Table 3 emphasize occurrences of doubt, self-criticism or direct request for the solution. For six of the seven interviewees, this procedure (broadly speaking) divides Table 3 into two zones. On the left, corresponding to a "beginning" (whose duration depends largely on the student), agreement is prevalent, even if it sometimes follows discussion of a particular LR with the interviewer.

At a certain point (right side of the table, Step 9 and later), students' certainties were shaken and destabilization often occurred, as judged by recurrences of already discussed LRs. Students also explicitly expressed their doubts and/or self-criticisms:

\author{
A 146,24 '10"' \\ - Ah yes, if we put silver the other side, not inside. \\ - That's it. \\ - Ah OK. Why do we have a higher temperature? It's me who said it? (selfc) \\ R 197, 31’05 \\ - You had argued a little like/ greenhouse effect/ It comes back/ Here I have seen how I could gain \\ more $\Delta \mathrm{T}$ downstream. Can I use this line of reasoning upstream? (d-selfc) \\ - The same one. \\ - I would tend to say no but I don't see any reason to object, then, err, I don't see any reason to \\ object. $(d-$ selfc $)$ \\ T 354, 43' \\ - Well I, I start having difficulty justifying, but/ Yes, reflective side inside but I believe I have \\ difficulty justifying. $(d-s e l f c)$
}

$\mathrm{H}$ can be distinguished from the others in that she very soon realized that there was a problem of consistency with her responses.

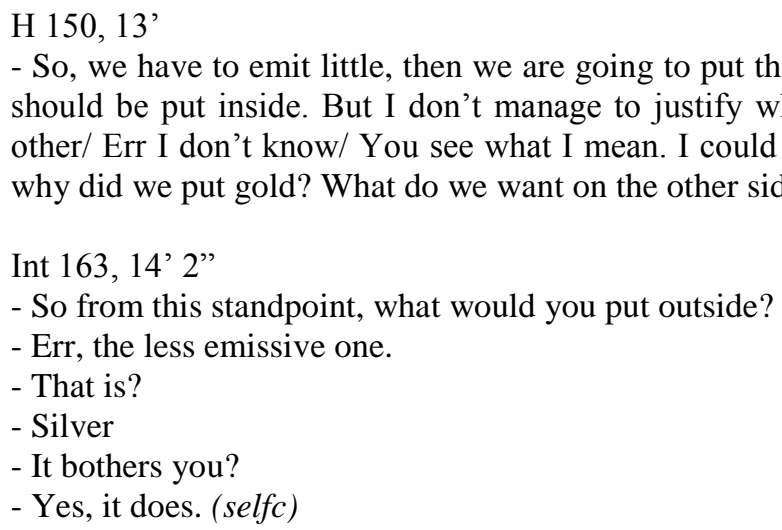

Int 163,14 ' 2"

- So from this standpoint, what would you put outside?

- Err, the less emissive one.

- That is?

- Silver

- It bothers you?

- Yes, it does. (selfc) should be put inside. But I don't manage to justify why, then the other, gold, should be put the other/ Err I don't know/ You see what I mean. I could perhaps justify one side, but the other one, why did we put gold? What do we want on the other side? A priori/ ( $d$-selfc)

Her preliminary conclusion (18 exchange turns later) shows that the target for this first part of her interview was practically reached after less than a quarter of an hour. During this first episode of the interview, she had taken a significant number of intellectual steps that other interviewees took much later. It is worth noting that, at the beginning of the interview, she knew very little about the phenomena under discussion, and she said that she simply relied on her intuition. But what she learned from the introductory experiment (see Box 2) was sufficient to trigger self-questioning of her first answer; this type of response was noticeably absent in the other students.

By the end of this first phase of the interview, all the students had finally acknowledged that they did not know the solution to the problem: 
- We don't know what's up. (d)

For all that, they did not necessarily discard their incomplete first responses. Only one student clearly formulated the need to search "where we can gain more" (R 220); the others admitted that they did not know how to move forward with this problem by means of qualitative reasoning.

\section{Main results: parts 2 and 3 of the interview}

When the interviewer introduced the mathematical model, the students raised no objection, nor did they express any particular difficulty; more or less rapidly, they recognized the analogy with an electric circuit. They were also more or less at ease with reasoning qualitatively about electric resistances in parallel, and with using the notion of a short-circuit to infer that, for a high total resistance, it was better to put the smallest resistances in parallel, in series with the greatest ones in parallel. The experimental setting with a discharging capacitor also seemed very convincing to all of them. The report on home experiments, though imprecise, completed the set of convincing arguments, and no serious obstacle was encountered in this phase of the interview.

Finally, students were asked their level of satisfaction with the interview, and more particularly about its global structure (qualitative dialogue first, followed by formal solution). There was a unanimous agreement on the value of starting with a qualitative discussion:

Int 553, 75

- If we had only done the calculation, for instance?

- Actually, we would've found the result more quickly, but, by the way, I had simply already done similar things, but finally I'm not able to respond with (natural) language/ Not necessarily well understood the essence of things, even if I am able/ If I have resistances I can draw resistances and find a ratio.

- Are you saying that we understand the meaning of things better...

- Yes yes

- ...when we have confronted the difficulty of natural language?

- Yes that's it.

A 396, 53'

I remember because I know, I remember by where I passed to know, otherwise how could I do?

Int 675,70

- Did you find it unpleasant, all this qualitative part, this discussion before doing the calculation?

- No, because on the contrary, it pleased me. If you start with calculations, it's done, we miss all the rest, we don't see the difficulties. No, it's much better like that.

R 392, 67'

- I am happy (...) I was able in this case to see what permitted to define the quantities of interest. Therefore I have learned something.

M 562, 54’25

- I liked it very much (...) If you see the calculation right away, then we are going to think, OK, I must reason like that, so err, it's a little biased, so.

- You mean that it dispenses you from asking yourself some questions?

- Yes.

The analogy with electricity was also positively appreciated

Int 497, 68'10"

- What about this analogy? Do you understand better? 
- I think it helps me understand electricity, I don't know whether this was the objective. I am happy because I have understood something (laughs).

- Actually I recognised it, you added inverses actually, I recognised it because I knew it, but it's convenient to use it when you see it like that.

Students' final level of satisfaction was strikingly high. Almost unanimously, they rated their level of intellectual satisfaction 3 or 4 on a scale from 1 (very low) to 4 (very high).

C 674, 80'30'

- Yes, it's fine, it's very very fine, I like it, and electrical analogy, it's fine. No, it's fine like that, me, I like it, it's fine.

M 410, 56'30"

- Ah yes I'm happy. I have seen something I didn't think of, actually, it's true that for me, survival blanket, it's silver inside and then/

H 750, 85,

- I want to manage to formulate conclusions on my own, that's my personal goal, therefore I was happy with respect to that.

At the same time, the complexity of the problem was acknowledged by several students.

C 610, 62'09"

- Yes yes yes I find this very interesting.

- It's hard however, no?

- Err then, hard? I wouldn't say it's hard, but there are many little mechanisms sometimes a little odd to be combined.

H 750,85 ,

- Also, the problem is difficult.

Finally, all were able to identify the weaknesses of the documents found online:

S 602, 68'30',

- In the rain, the argument is correct, we put gold outside.

- I see you have well / But if it's cold without rain?

- They don't say anything, they say "cold" as well, yes, they say "cold" (...)

S 612, 69'10"

- It's not complete, definitely!

T 564, 71'50"

- It's really/ I am shocked that no one has studied this among survival blanket manufacturers. I find it very odd, all the more so that/

C 662, 68'45"

- They say "cold", then if it's cold and dry, it's wrong!

R 410, 75,

- It's alarming!

\section{Recapitulation and final discussion}


This investigation offers some clues about obstacles to the comprehension of systems of the kind analysed here. Not surprisingly, we found a strong attraction-in this case, unanimous - to a line of reasoning centred on the journey of an entity ("heat"), proceeding from the body towards the external air, blocked by the strong reflective power of the silver side of the survival blanket. This argument fails to take account of what occurs between blanket and external air and therefore represents a very simple form of linear causal reasoning. The very existence of several compartments to be considered proved questionable for one student, which is a first clue that a system approach is not immediately obvious. Additionally, the implications of considering a stationary regime proved to be highly counterintuitive, even if the great majority of interviewees declared their preference for this approach to the problem. This suggests that it may be difficult to concede that, for a given value of the total flux transiting through the system, the emerging flux is necessarily the same regardless of the system's composition. In the same way, it is far from obvious that this stationary regime results from an adjustment between the energy transfers by conduction and convection on the one hand and radiant processes on the other, via the temperature of the blanket. These potential difficulties can all be attributed to the need for a system approach that takes account of retroactions and coupling. Analogous phenomena have previously been detected in students' explanations of the greenhouse effect; in that sense, this study may be seen as simply confirming, in detail and for this particular topic, some prevalent approaches to reasoning that are already well known.

In fact, this analysis was a prerequisite, informing our question about the possible codevelopment of conceptual understanding and metacognitive-critical-affective (MCA) processes in students' learning. The aim was to map students' pathways from an initial idea about the topic to a more complete analysis. The five recurrent lines of reasoning identified here served as conceptual markers. Some indicators of students' response to the various presented arguments were also defined, including two levels of approval, explicit doubt, silence, self-criticism and acceptance of the non-self-evidence of their first answer. This set of analytical tools was used to map students' intellectual dynamics in the first phase of the interviews - that is, until they became aware that answer the question posed (how to place the survival blanket, with justification) was not obvious.

Our results suggest that there may indeed be a strong interrelation between MCA aspects of students' intellectual pathways and their developing understanding of the topic. After the first experimental demonstration of the relative emissivity of silver and gold sides of the blanket (see Box 2), students might have realized that it would be advantageous to orient the weakly emissive side (silver) towards the external air. However, only one of the students, who had very little previous knowledge of this topic, quickly became aware that her first response (i.e. "silver inside") posed a problem in this regard. What she had learned from the introductory experiment was sufficient to trigger this self-questioning of her first answer-an intellectual trajectory that was noticeably absent in the other students. The minimal but logically sufficient conceptual hints at their disposal failed to prompt the other participants to critically examine their first response, and they took much longer to arrive at such a doubt. Students began to question their first answer when a reason that supported it-low net radiant flux in the internal zone of transfer - was also related to the external zone of transfer, so suggesting the opposite answer. Clearly, they had to be led, step by step, to an explicit contradiction in order to achieve some critical distance from their previous conception. Once this occurred, the discussion ceased to be characterized by ready agreement. In the absence of a satisfying explanation from the interviewer, some previous lines of reasoning were revisited, accompanied by expressions of frustration and self-criticism. At the end of the interview, all interviewees clearly and unanimously stated that a preceding qualitative discussion of the topic was of much greater value to them than simply being presented with a formal solution, 
however efficient that approach might seem. Given the repeated steps required for destabilization, such unanimous satisfaction was unexpected. Some metacognitive comments were very explicit concerning their reasons: "I remember by where I passed, otherwise, how could I do?" "If you start with calculations, it's done, we miss all the rest, we don't see the difficulties."

In summary, participants' critical attitude was observed to develop along with their comprehension of the topic while their comments regarding metacognition and intellectual satisfaction became increasingly explicit. This analysis provides strong arguments to support the thesis of a direct interplay between conceptual and critical aspects of students' development. In particular, it suggests that characterizing a student as 'having' a 'critical faculty' (or not) may be inappropriate. Willingham [28] had already challenged this idea, arguing that 'being critical' (or not) was strongly dependent on the conceptual content addressed and that 'Critical thinking is not a set of skills that can be deployed at any time, in any context'. Here, in examining the intellectual dynamics of a given student in relation to a given physical situation, the focus was on how they activate their critical potential. We suggest that such a research approach might fruitfully complement investigations of correlations between certain skills and the various indicators of conceptual achievement.

Turning to the implications for physics teaching, the present study has identified a number of tools that can be used (and adapted to different teaching contexts) to assess the extent to which learners share these lines of reasoning, as well as their readiness to activate their critical potential in this regard. These diagnostic tools include the topic selection; the (novel) content analysis and the electrical analogy proposed to model it; the interview protocol and the method used to map students' intellectual dynamics. Like other such tools relating to physics learning, these methods can help to enhance teachers' awareness of their students' needs and so inform the design of learning environments explicitly targeting those needs. That said, it is important to specify more precisely how objectives and strategies in physics education might benefit from the findings of this study. In terms of teaching objectives, the main finding here is that, to release interviewees' critical potential, a threshold of comprehension must be reached that is student-dependent and often higher than mere logical necessity. Granted the limitations of this study, our analysis strongly suggests that to disregard the objective of conceptual structuring would be counter-productive for the development of students' critical attitude (see also [29]).

It is not claimed here that higher conceptual achievement necessarily or always correlates with better activation of critical faculty; we have already noted reported cases of 'anesthesia of judgment' ([29], [30], [31]), in which experts were uncritical of incomplete or incoherent explanations despite having all the requisite knowledge to analyse them. These cases suggest that reaching a threshold of comprehension may be a necessary condition for enacting a critical faculty but not a sufficient one. In short, it must be conceded that aspects other than the conceptual must be considered in seeking the determinants of a critical attitude (or, in Eriksson et al.'s terminology, 'disciplinary discernment' [32]). As already noted, some students (only one in our small sample) were observed to enact a critical attitude based on very limited knowledge of the topic at hand-not a knowledge-based critical statement but an ability to recognise the insufficiency or incoherence of an explanation and to express one's frustration. This ability may rely in part on psychological factors such as self-esteem or exigency; in his characterization of 'human agency', Bandura [33] underlines the role of 'selfefficacy' in adaptation and change: 'Perceived self-efficacy occupies a pivotal role in the causal structure of social cognitive theory because efficacy beliefs affect adaptation and change not only in their own right, but through their impact on other determinants (...). Efficacy beliefs play a central role in the self-regulation of motivation through goal challenges and outcome expectations'. Acknowledging a lack of comprehension, or renouncing a 
previous idea, or else passing from a search for previous knowledge to a search for intelligibility may constitute challenging 'adaptations and changes' as mentioned in Bandura's analysis. We believe that a better understanding is needed of how students can be helped to feel more confident in using the knowledge and intellectual tools already at their disposal while remaining aware of their limitations; precisely how to design interactive scenarios to that end clearly warrants further research, and we believe that correlation-based studies are probably not enough. Instead, our findings support the need for in-depth analyses of students' intellectual dynamics - that is, of intervening processes during interaction with a teacher or with other students in the construction of critical judgments of the coherence and completeness of scientific explanations.

\section{Acknowledgements}

\section{References}

[1] European Commission 2015 Science Education for Responsible Citizenship Report EUR 26893 EN chair Hellen Hazelkorn Brussels

[2] Kuhn, D. 1991 The skills of arguments. Cambridge University Press.

[3] Flavell, J. H. 1987 Speculations about the nature and development of metacognition In F. E. Weinert \& R. Kluwe (Eds.) Metacognition, motivation, and understanding (pp. 21-29) Hillsdale, NJ: L. Erlbaum Associates.

[4] Zohar, A., \& Barzilai, S. 2013 A review of research on metacognition in science education: Current and future directions Studies in Science Education, 49(2), 121-169. doi:10.1080/03057267.2013.847261

[5] Vermunt J D 1996 Metacognitive, cognitive and affective aspects of learning styles and strategies: A phenomenographic analysis. Higher Education 31 25-50. doi:10.1007/BF00129106

[6] Jenkins E W 2007 School science: A questionable construct? Journal of Curriculum Studies 39 265-282 doi:10.1080/00220270701245295

[7] Ogborn, J. (1997). Constructivist metaphors of learning science. Science \& Education, 6, 121-133.

[8] Mathé S \& Author 12009 Stressing the coherence of physics: Students journalists' and science mediators' reactions Problems of education in the 21 st century 11(11) 104-128

[9] Author 12001 Reasoning in physics (chap. 5) Dordrecht: Kluwer

[10] Colin P 2011 Enseignement et vulgarisation scientifique: une frontière en cours d'effacement? Une étude de cas autour de l'effet de serre Spirale 48 63-84.

[11] Besson, U., De Ambrosis, A., \& Mascheretti, P. (2010). Studying the physical basis of global warming: Thermal effects of the interaction between radiation and matter and greenhouse effect. European Journal of Physics, 31, 375-388. doi:10.1088/01430807/31/2/015

[12] Besson U \& De Ambrosis A 2014 Teaching Energy Concepts by Working on Themes of Cultural and Environmental Value Science and Education 23 1309-1338.

[13] Komorek M \& Duit R 2004 The teaching experiment as a powerful method to develop and evaluate teaching and learning sequences in the domain of non-linear systems, International Journal of Science Education 26(5), 619-633.

[14] Author 11998 Experimental facts and ways of reasoning in thermodynamics: learners' common approach In A. Tiberghien: E-L Jossem and J Barojas Eds: Connecting Research in Physics Education with Teacher Education http://iupap-icpe.org/ 
[15] Erickson, G. (1985). Heat and Temperature, part A, In R. Driver, E. Guesnes \& A. Tiberghien (Eds.), Children's Ideas in Science (pp.52-84). Milton Keynes: Open University Press.

[16] Engel-Clough, E. \& Driver, R. (1985). Secondary students' conceptions of the conduction of heat: bringing together personal and scientific views. Physics

Education, 20, 176-182.

[17] Tiberghien, A. (1985), Heat and Temperature, part B, In R. Driver, E. Guesnes \& A. Tiberghien (Eds.), Childrens' Ideas in Science. (pp. 52-84). Milton Keynes: Open University Press.

[18] Lewis, E. L., \& Linn, M. C. (1994). Heat energy and temperature concepts of adolescents, adults, and experts: implications for curricular improvements. Journal of Research in Science Teaching, 31(6), 657-678.

[19] Yeo, S., \& Zadnik, M. (2001). Introductory thermal concept evaluation: assessing students' understanding. The PhysicsTeacher, 39(8), 496-504.

[20] Fauconnet, S. 1984. Etude de résolution de problèmes analogues, In A.Tiberghien 1984 (Ed.), Research on physics education : proceedings of the first international workshop, La Londe les Maures 1983 (pp. 261-269), Paris : CNRS.

[21] Driver, R., Guesnes, E. \& Tiberghien, A. (1985). Some Features of Children's Ideas and their Implications for Teaching, In R. Driver, E. Guesnes, \& A. Tiberghien (Eds.), Children's' Ideas in Science. (pp. 193-201). Milton Keynes: Open University Press.

[22] Rozier S. \& Viennot, L. (1991). Students' reasonings in thermodynamics. International Journal of Science Education, 13(2), 159-170.

[23] Author 1 \& Author 2 (2014). Which side to put the survival blanket? Analysis and suggestions for activities with students. Published by the MUSE group (More Understanding with Simple Experiments) in the Physics Education Division (PED) of the European Physical Society (EPS) http://www.eps.org/, education, MUSE.

[24] Besson, U. (2009). Paradoxes of thermal radiation, European Journal of Physics 30, 995 1007.

[25] Vollmer, M. 2009. Newton's law of cooling revisited. European Journal of Physics 30, 1063-1084

[26] Author $1 \&$ de Hosson, C. (2015. From a Subtractive to Multiplicative Approach, A Concept-driven Interactive Pathway on the Selective Absorption of Light, International Journal of Science Education, 37:1, 1-30. DOI: 10.1080/09500693.2014.950186

[27] Corbin, J., \& Strauss, A. 1990 Basics of qualitative research: Grounded theory procedures and techniques. Basics of qualitative research: Grounded Theory procedures and techniques, 41 London: Sage.

[28] Willingham, D.T. 2008 Critical Thinking: Why Is It So Hard to Teach?, Arts Education

Policy Review, 109:4, 21-32.

[29] Author 2 \& Author 1 2015. Co-development of conceptual understanding and critical attitude: analysing texts on radiocarbon dating, International Journal of Science Education, 37, 2038-2063 http://dx.doi.org/10.1080/09500693.2015.1061720.

[30] Author 1 (2006). Teaching rituals and students' intellectual satisfaction, Physics Education, 41, 400-408.

[31] Author 1 2013. Les promesses de l'Enseignement Intégré de Science et Technologie (EIST): de la fausse monnaie? Spirale $\mathrm{n}^{\circ}$ 52, 51-68.

[32] Eriksson, U., Linder, C., Airey, J., \& Redfors, A. (2014). Introducingthe anatomy of disciplinary discernment: an example from astronomy European Journal of Science and Mathematics Education, 2(3), 167-182.

[33] Bandura, A. (2001). Social cognitive theory: An agentic perspective. Annual review of psychology, 52(1), 1-26. 
[34] Brau, J. 2006. Transferts de chaleur et de masse, INSA de Lyon, GCU

http://ori-oai-search.insa-lyon.fr/notice/view/default\%253AUNIMARC\%253A160504

\section{Appendix 1. The survival blanket: a linear transfer model}

The model takes account of three subsystems: the body, the survival blanket and the external air (respectively: $\mathrm{T}_{\mathrm{o}}, \mathrm{T}_{\mathrm{b}}, \mathrm{T}_{\mathrm{e}}$ ), each of which is isothermal. This relies on the hypothesis that the time scale of temperature change is large with respect to the time scale of energy transfer inside the body [25] - in other words, the conductivity inside the body is very high by comparison with the other conductivities in play. Body and external air are separated by two zones filled with air (see text, Fig. 1); the most external one is the boundary layer in a situation of convective transfer. The transfer of the energy in these two zones is linked to a temperature gradient. An approximation expressing the net radiant flux between two bodies as a linear function of their temperature difference has been extensively discussed by Vollmer [25]; it will be assumed that such a linear treatment can be appropriately implemented. With regard to the conductive-convective flux, a linear treatment is commonly accepted [34].

Let $C^{\prime}, C$ be the coefficients of net thermal transfer via conduction and convection (C), respectively in the upstream and downstream part of the system; and let $A^{\prime}, A$ be the coefficients of net radiant transfer respectively upstream and downstream the blanket (for each side of the blanket concerned, silver or gold, $A_{\mathrm{s}}, A_{\mathrm{g}}$ respectively). All these coefficients depend in particular on shape factors.

Due to stationary state,

$\Phi=\left(\mathrm{C}^{\prime}+\mathrm{A}^{\prime}\right)(\mathrm{To}-\mathrm{Tb})=(\mathrm{C}+\mathrm{A})(\mathrm{Tb}-\mathrm{Te})$

Local implications:

$\begin{array}{llll}\text { For silver outside } & \Phi=\left(C+A_{\mathrm{s}}\right)\left(T b_{s}-T e\right) & \text { then } & T b_{\mathrm{s}}-T e=\Phi /\left(C+A_{s}\right) \\ \text { and } & \Phi=\left(C^{\prime}+A^{\prime}{ }_{g}\right)\left(T o-T b_{s}\right) & \text { then } & T o-T b_{s}=\Phi /\left(C^{\prime}+A^{\prime}{ }_{g}\right) \\ \text { For gold outside } & \Phi=\left(C+A_{\mathrm{g}}\right)\left(T b_{g}-T e\right) & \text { then } & T b_{\mathrm{g}}-T e=\Phi /\left(C+A_{\mathrm{g}}\right) \\ \text { and } & \Phi=\left(C^{\prime}+A_{s}^{\prime}\right)\left(T o^{-} T b_{g}\right) & \text { then } & T o^{-} T b_{g}=\Phi /\left(C^{\prime}+A_{s}^{\prime}\right)\end{array}$

From equations (2) and (4), we deduce that, given $\Phi, T e, C, A_{\mathrm{s}}$ and $A_{\mathrm{g}}$, the temperature of the blanket, $T b$, depends only on which side of the blanket faces outward.

Given that $A_{\mathrm{s}}<A_{\mathrm{g}}$, we have $T b_{\mathrm{s}}>T b_{\mathrm{g}}$, which means that turning the silver side outward will increase $T b$ with respect to the case when gold is outside. The difference $T b_{\mathrm{s}}-T b_{\mathrm{g}}$ will be all the larger as $C$ is small (dry and calm weather).

In case of a high value of $C$ due to wind and/or rain, then we have

$\mathrm{C} \gg \mathrm{A}_{\mathrm{s}}, \mathrm{A}_{\mathrm{g}, \quad} \quad$ then $\mathrm{Tb}_{\mathrm{s}} \sim \mathrm{Tb}_{\mathrm{g}} \sim \mathrm{Te}$.

Regardless of which side faces outward, the temperature of the blanket is practically that of the external air.

Similarly, from equations (3) and (5) (see also Figure 3b), we deduce that, given $\Phi, T b, C^{\prime}, A_{\text {s }}^{\prime}$ and $A_{\mathrm{g}}^{\prime}$, the temperature of the body, $T o$, depends only on which side of the blanket faces inward. The value of $T o-T b$ will be all the larger, as $C^{\prime}+A^{\prime}$ ' will be small. Given $C^{\prime}, T o-T b$ will be largest when $A^{\prime}$ is as small as possible - that is, with the silver side facing inward. The difference $T o-T b$ will be all the larger as $C^{\prime}$ is small (i.e. air layer with dry and calm conditions between body and blanket).

As the blanket has only one silver side, it is impossible to maximize both $T o-T b$ and $T b-T e$ at the same time. However, what we seek to maximize, given $\Phi, T e, C, C^{\prime}, A_{\mathrm{s}}, A_{\mathrm{g}}, A_{\mathrm{s}}^{\prime}, A_{\mathrm{g}}^{\prime}$, is not the 
temperature of the blanket or the difference $T o-T b$ but the temperature of the body-or, equivalently, the value of $T o-T e$.

To solve this problem, we must analyse the system as a whole.

Treatment for the whole system

Let $G$ be defined by $\Phi=G(T o-T e)$

This is equivalent to $\frac{1}{G}=\frac{1}{C^{\prime}+A^{\prime}}+\frac{1}{C+A}$

For the highest possible value of $T o-T e$, given $\Phi$, we need to minimize $G$, given $C, C^{\prime}, A, A^{\prime}$, by choosing which side to turn outward (silver or gold). That is to say, we must compare

$\frac{1}{G_{\mathrm{g}}}=\frac{1}{C^{\prime}+A_{\mathrm{s}}^{\prime}}+\frac{1}{C+A_{\mathrm{g}}}$ (gold outside) and

$\frac{1}{G_{\mathrm{S}}}=\frac{1}{C^{\prime}+A^{\prime} \mathrm{g}}+\frac{1}{C+A_{\mathrm{S}}}($ silver outside $)$.

Each of these expressions can be seen as the "total resistance" for the energy transfer from object to external air in each situation. The largest value designates the most favourable case for protecting the body against cold.

We now see that, provided we consider a quasi-static situation - that is, with the same power flux along the system at a given time-two possible formulations of the problem lead to the same solution.

In case of steady state with $\Phi$ constant in time, the temperature of the body, To, has the highest possible value when $G$ is minimum.

In case of a given temperature of the body, To, the minimum value of $\Phi$ is when $G$ is minimum.

How then can we find the most favourable case? By making a supplementary hypothesis of identical shape factors for the emission of a given side (downstream or upstream) - certainly the most contestable hypothesis in this simple model-simple calculations may give an idea of the best compromise.

- If the shape factors are taken as equal, $A_{\mathrm{s}}^{\prime}=A_{\mathrm{s}}$ and $A_{\mathrm{g}}^{\prime}=A_{\mathrm{g}}$, then we must compare the "total resistances":

$\frac{1}{G_{\mathrm{g}}}=\frac{1}{C^{\prime}+A_{\mathrm{s}}}+\frac{1}{C+A_{\mathrm{g}}}($ gold outside $)$ and

$\frac{1}{G_{\mathrm{s}}}=\frac{1}{C^{\prime}+A_{\mathrm{g}}}+\frac{1}{C+A_{\mathrm{s}}}($ silver outside $)$

If $C=C^{\prime}$, the two expressions take the same value, whatever $A_{\mathrm{s}}$ and $A_{\mathrm{g}}$, and the two situations are equivalent in protecting against cold.

In order to compare the "total resistances" in the two situations, we can also compare the "total conductances", $G_{\mathrm{g}}$ and $G_{\mathrm{s}}$. As the best compromise is the one corresponding to the lowest value of $G$, we have to calculate:

$$
\begin{gathered}
G_{\mathrm{s}}-G_{\mathrm{g}}=\frac{\left(C^{\prime}+A_{\mathrm{g}}\right)\left(C+A_{\mathrm{s}}\right)}{C^{\prime}+A_{\mathrm{g}}+C+A_{\mathrm{s}}}-\frac{\left(C^{\prime}+A_{\mathrm{s}}\right)\left(C+A_{\mathrm{g}}\right)}{C^{\prime}+A_{\mathrm{s}}+C+A_{\mathrm{g}}} \\
G_{\mathrm{s}}-G_{\mathrm{g}}=\frac{\left(C-C^{\prime}\right)\left(A_{\mathrm{g}}-A_{\mathrm{s}}\right)}{C^{\prime}+A_{\mathrm{g}}+C+A_{\mathrm{s}}}
\end{gathered}
$$

As above, if $C=C^{\prime}$, then both situations (gold outside or silver outside) are equivalent in protecting against cold, whatever the values of $A_{\mathrm{s}}$ and $A_{\mathrm{g}}$.

If not, given that $A_{\mathrm{g}}>A_{\mathrm{s}}$, the sign of $G_{\mathrm{s}}-G_{\mathrm{g}}$ is the same as the sign of $C-C^{\prime}$.

In practice, in case of conditions favouring high conductive-convective thermal transfer outside the blanket ( $C^{\prime}<C$, wind and rain, $G_{\mathrm{g}}<G_{\mathrm{s}}$ ), the gold side of the blanket should face outward; in the opposite case $\left(C^{\prime}>C\right.$, dry and calm weather), the silver side should be face outward. 
Appendix 2. Some home experiments

Several home experiments with the same body wrapped with the emergency blanket material (silver outside versus gold outside) were carried out by one of the authors. Some results with hot water in a freezer $\left(-17^{\circ} \mathrm{C}\right)$ and two sets of values for volume of water, initial temperature and cooling time are given in Tables 3 and 4. The simple materials used are shown in Figure 6.

Given that the inside of the freezer can be seen as a calm and dry environment, the results confirm the previous analysis, indicating less cooling with silver outside. However, the differences in final temperature are not large when compared to the fluctuations when replicating a given experiment. During a short teaching session, it may be difficult to devote the necessary time to reach a safe conclusion, and this topic may be more appropriate to a student project.

Table 4. Final temperature of $210 \mathrm{~cm}^{3}$ of water in a plastic bowl, with some air above, in a bag made of emergency blanket (gold or silver outside), starting from $38{ }^{\circ} \mathrm{C}$, after an hour in a freezer at $-17{ }^{\circ} \mathrm{C}$. The experiment was performed four times (corresponding to rows of the Table).

\begin{tabular}{ll}
\hline "Gold" outside & "Silver" outside \\
\hline $12.5^{\circ} \mathrm{C}$ & $15^{\circ} \mathrm{C}$ \\
\hline $13^{\circ} \mathrm{C}$ & $16^{\circ} \mathrm{C}$ \\
\hline $12{ }^{\circ} \mathrm{C}$ & $15^{\circ} \mathrm{C}$ \\
\hline $13^{\circ} \mathrm{C}$ & $16^{\circ} \mathrm{C}$ \\
\hline
\end{tabular}

Table 5. Final temperature of $65 \mathrm{~cm}^{3}$ of boiling water, filling up a plastic box, covered with emergency blanket (gold or silver outside), after $20 \mathrm{~min}$ in a freezer at $-17^{\circ} \mathrm{C}$. The experiment was performed four times (corresponding to rows of the Table).

\begin{tabular}{cl}
\hline "Gold" outside & "Silver" outside \\
\hline $39{ }^{\circ} \mathrm{C}$ & $44^{\circ} \mathrm{C}$ \\
\hline $40{ }^{\circ} \mathrm{C}$ & $43^{\circ} \mathrm{C}$ \\
\hline $38^{\circ} \mathrm{C}$ & $43^{\circ} \mathrm{C}$ \\
\hline $39^{\circ} \mathrm{C}$ & $44^{\circ} \mathrm{C}$
\end{tabular}

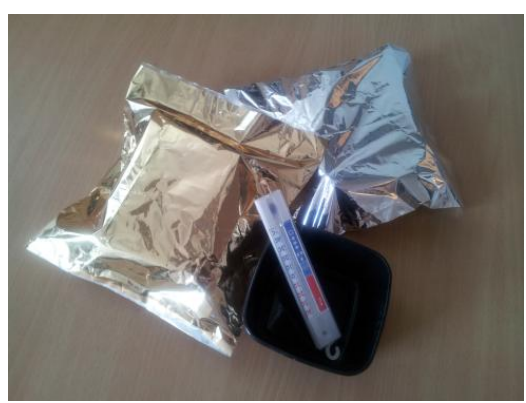

A

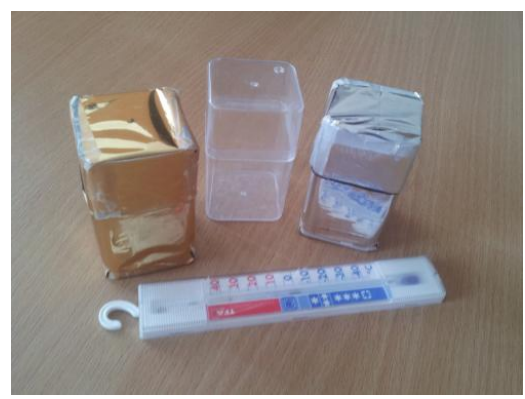

B

Figure 3. Simple materials for home experiments (a: see Table 3; b: see Table 4).

In the case of windy and rainy weather, with $65 \mathrm{~cm}^{3}$ of boiling water, filling up a plastic box, covered with emergency blanket, (gold or silver outside), after $15 \mathrm{~min}$ on a balcony, almost identical final temperatures were obtained twice in succession during a stormy day $\left(38.4{ }^{\circ} \mathrm{C}\right.$ for the first experiment and $38.1{ }^{\circ} \mathrm{C}$ for the second). This fits the case of very high convection-conduction coefficients as analysed above. While the preceding results are consistent with the previous analysis, home experiments are unlikely to be sufficient to explore all possible cases, especially that of high external conduction. 
